\title{
Research on Optical Fiber Sensor for Environmental Temperature and Humidity of Transmission Line
}

\author{
Jie Zhang ${ }^{1}$, Yan Xie ${ }^{1 *}$, Zehua Zhang ${ }^{1}$, Le Lv ${ }^{1}$, and Zhencheng Tan ${ }^{1}$ \\ ${ }^{1}$ School of Electrical and Electronic Engineering, Wuhan Polytechnic University, Hubei, China
}

\begin{abstract}
The operation environment of the transmission line directly affects the operation safety of the transmission line. This article studied a FBG temperature and humidity sensor based on optical fiber sensing technology for transmission lines. Firstly, this paper studies the packaging method of the sensor, then designs the corresponding installation fixture, and gives its installation diagram. Finally, the performance of the FBG is tested in the experimental box and the national optoelectronic information product quality supervision and inspection center, and the test results show that the performance of the FBG temperature and humidity sensor is better.
\end{abstract}

\section{Introduction}

In the actual operation of the power system, the operation environment of the transmission line directly affects the operation safety of the transmission line, such as the temperature, humidity, wind direction, wind speed, tower inclination and so on. Transmission line environmental conditions have a vital impact on the safe operation, and the change of these conditions is often one of the factors causing transmission failure. Therefore, the real-time monitoring of transmission line environmental parameters is very important.

The operation and maintenance department of transmission line needs to monitor the environmental state of transmission line in real time to find out the abnormal temperature and humidity of the operating environment of transmission line in time, so as to avoid the occurrence of safety accidents. Traditional temperature and humidity monitoring methods, such as thermocouple temperature measurement and electrical humidity measurement technology, have poor anti electromagnetic interference and insulation ability, so their applicability is poor.

In this paper, Fiber Bragg grating (FBG) is used to monitor the environmental temperature and humidity of transmission line. The advantages of FBG, such as intrinsic insulation, anti-electromagnetic interference, corrosion resistance and stable performance, will be used to realize real-time and effective monitoring of the environmental temperature and humidity of transmission line.

\section{Structure design of sensor}

\subsection{Design of packaging method}

Due to the poor sensitivity of FBG to humidity changes, the wavelength shift of light is very small. In order to be sensitive to humidity effectively, a layer of humidity sensitive material (such as carbon fiber composite or polyimide) should be coated on the outer surface of the optical fiber. The structure is shown in Figure 1.

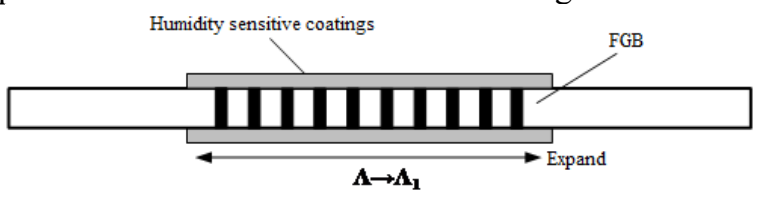

Fig 1. Coating structure of humidity sensitive materials

When the environmental humidity changes, the fiber Bragg grating will respond to the strain due to the expansion of the humidity sensitive material coated on the fiber surface, which transforms the environmental humidity sensing problem into the response of the fiber Bragg grating to the strain.

Moisture sensitive materials will expand after moisture absorption. The strain of FBG caused by moisture absorption is called wet strain. It can be expressed as:

$$
\varepsilon_{M}=\int_{0}^{\Delta Y} \beta(Y, T) d y
$$

Where, $\beta$ is the hydroscopic expansion coefficient of the composite composed of humidity sensitive material and optical fiber, and $Y$ is humidity.

According to the elastic theory, the hydroscopic expansion coefficient can be deduced as follows:

\footnotetext{
* Corresponding author: xyy@whpu.edu.cn
} 


$$
\beta(Y, T)=\beta_{M}\left(1-\frac{C_{0} E_{F} V_{F}}{E_{F} V_{F} / E_{M} V_{M}}\right)
$$

Where, $\beta_{M}, E_{M}$ and $V_{M}$ are the hydroscopic expansion coefficient, volume and elastic modulus of the humidity sensitive material respectively. $V_{F}$ and $E_{F}$ are the volume and elastic modulus of the fiber grating. $C o$ is the bonding coefficient between the humidity sensitive material and the fiber.

Taking $V_{F}=\pi r_{F}^{2}$ and $V_{M}=\pi r_{M}{ }^{2}$ into the above formula, the following results are obtained:

$$
\beta(Y, T)=\beta_{M}\left(1-\frac{E_{F} r_{F}^{2}}{E_{F} r_{F}^{2}+E_{M}\left(r_{M}^{2}-r_{F}^{2}\right)} \cdot C_{0}\right)
$$

The strain of the optical fiber can be obtained as follows:

$$
\begin{gathered}
\varepsilon_{M}=\beta_{M}\left(1-\frac{E_{F} r_{F}^{2}}{E_{F} r_{F}^{2}+E_{M}\left(r_{M}^{2}-r_{F}^{2}\right)} \cdot C_{0}\right) \Delta Y \\
C_{1}=1-\frac{E_{F} r_{F}^{2}}{E_{F} r_{F}^{2}+E_{M}\left(r_{M}^{2}-r_{F}^{2}\right)} \bullet C_{0}
\end{gathered}
$$

Then, the formula (4) can be abbreviated as:

$$
\varepsilon_{M}=\beta_{M} C_{1} \Delta Y
$$

So far, it can be seen that as long as the Bragg reflection wavelength shift of the fiber Bragg grating in Figure 1 can be measured, the influence of humidity can be determined in combination with formula (6). However, FBG is sensitive to temperature as well as stress, so it is necessary to compensate temperature for humidity measurement. When temperature compensation is carried out, the influence of temperature on FBG and humidity sensitive material should be considered. When the temperature changes, the periodic change of FBG caused by thermal expansion is as follows:

$$
\frac{\Delta \Lambda}{\Lambda}=a_{F} \bullet \Delta T
$$

Where, $\alpha_{F}$ is the coefficient of thermal expansion. When the temperature changes, the change of grating effective refractive index caused by thermos-optic effect is as follows:

$$
\frac{\Delta n_{e f f}}{n_{e f f}}=\xi_{F} \bullet \Delta T
$$

Therefore, the Bragg wavelength shift caused by temperature change can be obtained as follows:

$$
\frac{\Delta \lambda_{B}}{\lambda_{B}}=\left(a_{F}+\xi_{F}\right) \cdot \Delta T
$$

Because the change of temperature can also cause the thermal expansion of humidity sensitive materials, the effect of thermal expansion on the strain of fiber Bragg grating can be expressed as follows:

$$
\varepsilon_{T}=\left(a_{M}-a_{F}\right) \bullet \Delta T
$$

Where, $\varepsilon_{T}$ is the strain caused by the thermal expansion of the humidity sensitive material, $\alpha_{M}$ is the thermal expansion coefficient of the humidity sensitive material, and $\alpha_{F}$ is the thermal expansion coefficient of the optical fiber.

Considering the influence of temperature, the actual FBG Bragg reflection wavelength shift can be obtained by combining equations (7-10) :

$\frac{\Delta \lambda_{B}}{\lambda_{B}}=\left(1-p_{e}\right) C_{1} \beta_{M} \Delta Y+\left[\left(1-p_{e}\right)\left(a_{M}-a_{F}\right)+a_{F}+\xi_{F}\right] \Delta T$

Let $K_{T}=\left(1-p_{\varepsilon}\right)\left(\alpha_{M}-\alpha_{F}\right)+\alpha_{F}+\xi_{F}$ and $K_{M}=\left(1-p_{\varepsilon}\right)$ $C_{1} \beta_{M}$, then the above formula can be abbreviated as:

$$
\frac{\Delta \lambda_{B}}{\lambda_{B}}=K_{M} \Delta Y+K_{T} \Delta T
$$

It can be seen from the formula (12) that the wavelength shift caused by temperature and humidity acting on the fiber Bragg grating is linear superposition. In order to obtain accurate humidity sensing, it is necessary to know the response of the fiber Bragg grating to temperature. For this reason, we designed to write two gratings on the same fiber and coat them with humidity sensitive coating.

As shown in Figure 2, FBG1 can respond to both temperature and humidity. A layer of temperature sensitive material (such as aluminum) is attached to the outer surface of FBG2 to isolate the humidity sensitive coating from the influence of humidity and respond to temperature.

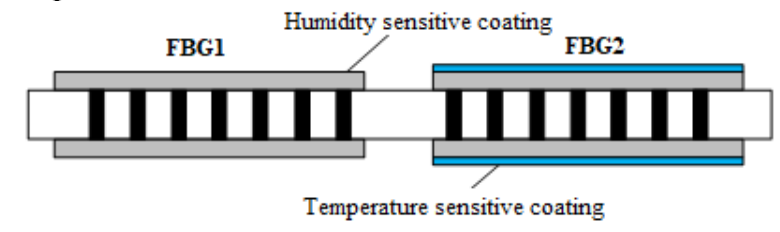

Fig 2. Structure of temperature and humidity fiber Bragg grating sensor.

The wavelength shift of two fiber gratings can be calculated according to equation (12).

$$
\begin{gathered}
\frac{\Delta \lambda_{B 1}}{\lambda_{B 1}}=K_{T 1} \Delta T+K_{M 1} \Delta Y \\
\frac{\Delta \lambda_{B 2}}{\lambda_{B 2}}=K_{T 2} \Delta T
\end{gathered}
$$

Therefore, by measuring the wavelength shift of FBG, the temperature change $\Delta T$ and humidity change $\Delta Y$ can be obtained.

\subsection{Design of installation fixture}

The types of sensors installed at the low voltage end of the tower include temperature and humidity sensor, wind speed sensor, angle sensor, tension sensor, insulator wind deflection sensor, etc. Among them, the temperature and humidity sensor, wind speed sensor and angle sensor are installed on the cross arm of the tower through the combination of cylindrical platform. The tension sensor and the insulator wind deflection sensor 
are installed on the upper end of the insulator string with a hoop clamp. The angle sensor installed at $2 / 3$ height of tower adopts the simplified design of cylindrical integrated platform.

On the cylindrical platform, only one temperature and humidity sensor is installed, which is located at the top of the cylinder, and is fixed on the mounting plate by three screw rods at the bottom. The mounting plate needs to be installed horizontally, and its base is a circle. The size of the base is related to the size of the sensor, and the size of the base is fixed. The size of the bracket fixing the base to the tower material will be different because of the size of the tower material. The specific design drawing is shown in Figure 3 to monitor the temperature and humidity of the surrounding environment at the top of the tower. Figure 4 is the schematic diagram of equipment installation.

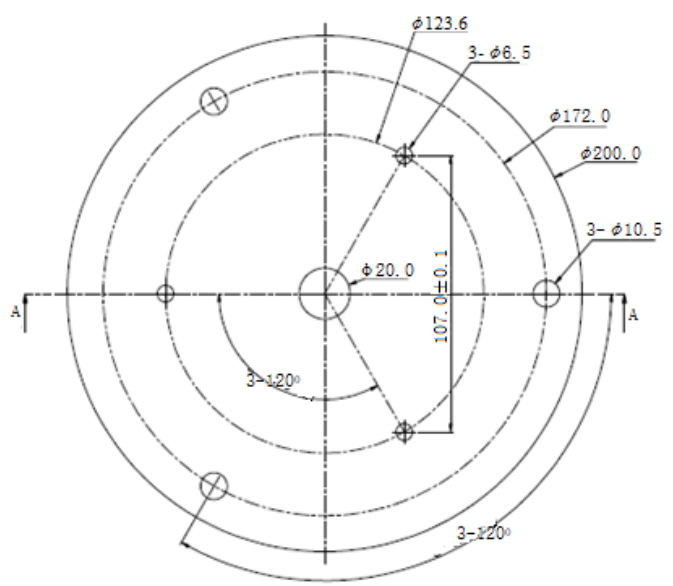

Fig 3.Installation of circular base for ambient temperature and humidity sensor

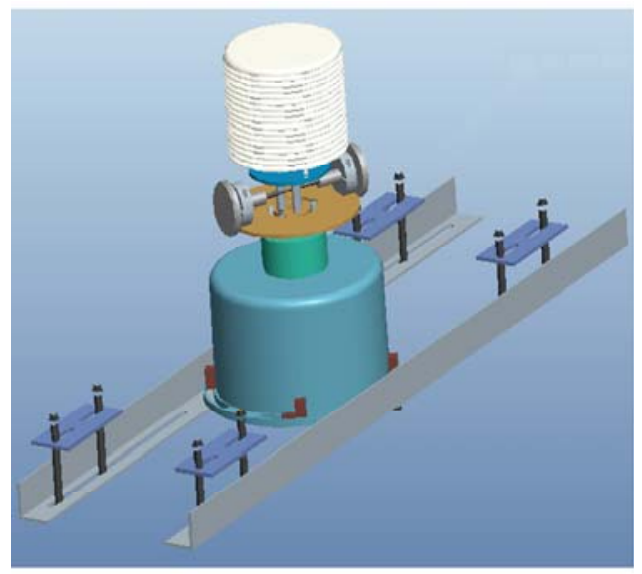

Fig 4. Schematic diagram of equipment installation

\section{Characteristic test and analysis}

The FBG temperature and humidity sensing test system is composed of light source, optical circulator, sensor and FBG demodulation module, as shown in Figure 5.

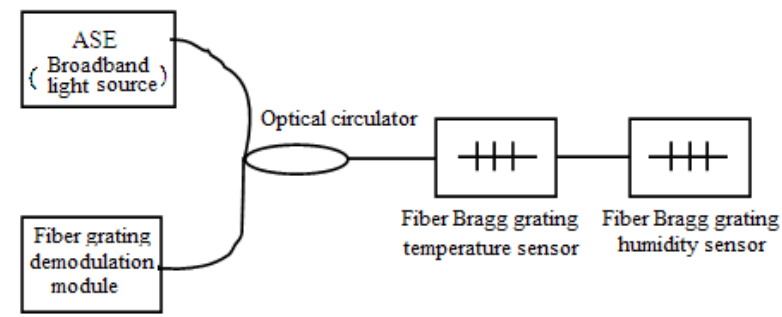

Fig 5.Temperature and humidity sensing system based on Fiber Bragg grating.

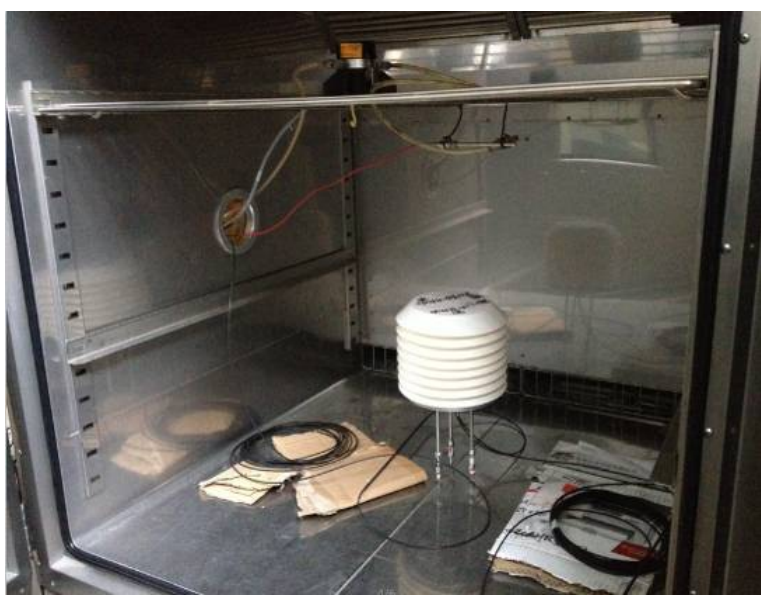

Fig 6. Temperature and humidity test.

The broadband light from ASE broadband light source enters through port 1 of optical circulator and then enters into the fiber grating temperature and humidity sensor through port 2 of optical circulator. The narrow-band light reflected by fiber grating enters into the fiber grating demodulation module through port 3 of optical circulator. Fiber Bragg grating temperature and humidity sensor is placed in a programmable constant temperature and humidity test box. After changing the temperature or humidity of the test box, the change of fiber Bragg grating center wavelength is detected by fiber Bragg grating demodulation module.

Through the above measurement system, the temperature and humidity sensor of fiber Bragg grating is tested. Figure 6 shows the actual wiring diagram of the test box.

The test chamber used in this test is a programmable constant temperature and humidity test chamber produced by Guangzhou dongzhixu Test Equipment Co., Ltd. the temperature measurement range of the constant temperature and humidity test chamber is $-20^{\circ} \mathrm{C} \sim 150^{\circ} \mathrm{C}$, and the humidity measurement range is $20 \% \mathrm{RH} \sim 98 \%$ RH. Place the temperature and humidity sensor in the temperature and humidity box, set the temperature at $15^{\circ} \mathrm{C}, 20^{\circ} \mathrm{C}$ and $30^{\circ} \mathrm{C}$, and select the standard $40 \% \mathrm{RH}$, $60 \% \mathrm{RH}$ and $80 \% \mathrm{RH}$ to test the temperature and humidity sensor. The test results are shown in Table 1 and Table 2. 
Table 1. Humidity sensor test data.

\begin{tabular}{|c|c|c|c|c|}
\hline $\begin{array}{c}\text { Test } \\
\text { point } \\
(\% \mathrm{RH}) \\
\end{array}$ & $\begin{array}{c}\text { Standard } \\
\text { value } \\
(\% \mathrm{RH}) \\
\end{array}$ & $\begin{array}{c}\text { Test } \\
\text { value } \\
(\% \mathrm{RH})\end{array}$ & $\begin{array}{c}\text { Error } \\
(\% \mathrm{RH})\end{array}$ & $\begin{array}{c}\text { Maximum } \\
\text { error } \\
(\% \mathrm{RH}) \\
\end{array}$ \\
\hline $40\left(15^{\circ} \mathrm{C}\right)$ & 44 & 48 & 4 & \multirow{9}{*}{11} \\
\hline $60\left(15^{\circ} \mathrm{C}\right)$ & 61 & 59 & -2 & \\
\hline $80\left(15^{\circ} \mathrm{C}\right)$ & 74 & 72 & -2 & \\
\hline $40\left(20^{\circ} \mathrm{C}\right)$ & 40 & 51 & 11 & \\
\hline $60\left(20^{\circ} \mathrm{C}\right)$ & 60 & 61 & 1 & \\
\hline $80\left(20^{\circ} \mathrm{C}\right)$ & 77 & 81 & 4 & \\
\hline $40\left(30^{\circ} \mathrm{C}\right)$ & 40 & 38 & -2 & \\
\hline $60\left(30^{\circ} \mathrm{C}\right)$ & 60 & 58 & -2 & \\
\hline $80\left(30^{\circ} \mathrm{C}\right)$ & 80 & 83 & 3 & \\
\hline
\end{tabular}

As we can see from table 1, the error of humidity sensor is relatively large, and the maximum error is $11 \%$ $\mathrm{RH}$, but it is not far from the standard error within $10 \%$. And only one of the nine groups of test data is $11 \% \mathrm{RH}$,

most of them are in $2 \sim 4 \% \mathrm{RH}$, which meets the requirements of the standard as a whole.

Table 2. Temperature sensor test data.

\begin{tabular}{|c|c|c|c|c|}
\hline $\begin{array}{c}\text { Test } \\
\text { point } \\
\left({ }^{\circ} \mathrm{C}\right)\end{array}$ & $\begin{array}{c}\text { Standard } \\
\text { value } \\
\left({ }^{\circ} \mathrm{C}\right)\end{array}$ & $\begin{array}{c}\text { Test } \\
\text { value } \\
\left({ }^{\circ} \mathrm{C}\right)\end{array}$ & $\begin{array}{c}\text { Error } \\
\left({ }^{\circ} \mathrm{C}\right)\end{array}$ & $\begin{array}{c}\text { Maximum } \\
\text { error } \\
\left({ }^{\circ} \mathrm{C}\right)\end{array}$ \\
\hline 15 & 14.8 & 14.7 & -0.2 & \multirow{2}{*}{-0.2} \\
\hline 20 & 19.9 & 19.8 & -0.1 & \multirow{2}{*}{. } \\
\hline 30 & 29.8 & 29.6 & -0.2 & \\
\hline
\end{tabular}

Through the temperature sensor test data sheet, we can find that the temperature sensor error is small, only $0.2^{\circ} \mathrm{C}$.

The environmental temperature and humidity sensor developed in this paper has been tested in the national optoelectronic information product quality supervision and inspection center. The test results are shown in Table 3 , and the measured values meet the technical requirements of the task specification.

Table 3. Third party inspection results of environmental temperature and humidity sensor.

\begin{tabular}{|c|c|c|c|c|}
\hline Name of sample & Inspection items & $\begin{array}{l}\text { Requirements of } \\
\text { mission statement }\end{array}$ & Measured value & Test conclusion \\
\hline \multirow{2}{*}{$\begin{array}{l}\text { Environmental } \\
\text { temperature sensor }\end{array}$} & Measuring range & $-40^{\circ} \mathrm{C}-50^{\circ} \mathrm{C}$ & $-40^{\circ} \mathrm{C}-50^{\circ} \mathrm{C}$ & \multirow{4}{*}{$\begin{array}{l}\text { Meet the } \\
\text { standard }\end{array}$} \\
\hline & $\begin{array}{l}\text { Measurement } \\
\text { accuracy }\end{array}$ & $\pm 1^{\circ} \mathrm{C}$ & $\pm 1^{\circ} \mathrm{C}$ & \\
\hline \multirow{2}{*}{$\begin{array}{l}\text { Environmental } \\
\text { humidity sensor }\end{array}$} & Measuring range & $0 \%$ RH- $100 \%$ RH & $0 \%$ RH- $100 \%$ RH & \\
\hline & $\begin{array}{l}\text { Measurement } \\
\text { accuracy }\end{array}$ & $\pm 4 \% \mathrm{RH}$ & $\pm 4 \% \mathrm{RH}$ & \\
\hline
\end{tabular}

\section{Conclusion}

In order to ensure the stable operation of transmission line, a temperature and humidity sensor based on fiber Bragg grating is studied. Firstly, its structure is designed. Two gratings are written into the same fiber and coated with humidity sensitive coating. One FBG can respond to temperature and humidity at the same time, and a layer of temperature sensitive material is attached to the other FBG, so that the humidity sensitive coating is not affected by humidity. By measuring the wavelength shift of FBG, the temperature and humidity can be obtained. Then the fixture structure is designed.

The performance of FBG temperature and humidity sensor is tested. When the temperature is kept at a fixed value, the central wavelength of FBG is tested under different humidity conditions. Keeping the humidity at a fixed value, the central wavelength of temperature fiber Bragg grating was measured under different temperature conditions. The test results show that the performance of the FBG temperature and humidity sensor is better.

\section{References}

1. Y. Jun, Z. Changsheng, L. Shibin, Research on transmission line micro-meteorological monitoring temperature and humidity sensor. Electric Power Science and Engineering, 34(2018)
2. Y. Yang, Development and application of online monitoring system for $110 \mathrm{kV}$ transmission lines in Shengli oilfield. Electronic Design Engineering, 29(2021).

3. G. Lin-lin , W. Qing-lin, G. Yun-li, Y. Hui, J. Ming-shun, Fabrication and Performance of Optical Fiber GratingSensors Packaged in Composite Substrate. Material engineering, 9(2018)

4. Z. Zhi, Z. Xuefeng, W. Zhanjun, et al. Study on $F B G$ sensor 's steel capillary encapsulating technique and sensing properties. Chinese Journal of Lasers, 29(2002)

5. W. Rujun, Z. Bailin, H. Pengfei, et al. Influence of encapsulation structures for embedded fiber-optic Bragg grating sensor on strain measurement. Optics and Precision Engineering, 22(2014)

6. G. Linlin, W. Qinlin, W. Xiaoxia, et al. Protection technology of optical fiber grating sensors embedded in fiber composite laminates. Acta Materiae Compositae Sinica, 33(2016) 